\title{
OBSTÁCULOS PARA EXPANSÃo dO USO DOS E-BOOKS NA SOCIEDADE BRASILEIRA
}

\begin{tabular}{cc}
\hline OBSTACLES FOR EXPANSION OF THE \\
USE OF E-BOOKS IN SOCIETY BRAZILIAN \\
\hline OBSTÁCULOS PARA LA EXPANSIÓN \\
DE E-BOOKS EN LA SOCIEDAD BRASILEÑA \\
\hline
\end{tabular}

\section{RESUMO}

O trabalho aborda as dificuldades para expansão do uso dos e-books na sociedade brasileira, principalmente, nas bibliotecas universitárias. Através de uma investigação baseada nos processos de seleção, aquisição, gestão e formação de acervos de suporte de natureza digital busca-se oferecer um diagnóstico objetivo acerca dos obstáculos encarados para ampliação do uso dos e-books. Pretende-se proporcionar formas para democratização do acesso, bem como, o arrolamento de processos simplificados acerca da administração de coleções. Almeja-se a partir desse estudo, expor procedimentos que facilitem a redução dos recursos financeiros e humanos que envolvem o gerenciamento dos e-books nas bibliotecas. A partir da redução dos processos e custos visa-se o aperfeiçoamento dos produtos e serviços oferecidos para a comunidade acadêmica. Nesse sentido, este trabalho representa uma pesquisa relevante para os profissionais da Biblioteconomia e da Ciência da Informação. O caminho metodológico aplicado foi a revisão de literatura acerca do tema proposto nos campos das Ciências da Informação, mais especificamente, da Biblioteconomia. Esse modelo de pesquisa possibilita ampliar a proporção do conhecimento existente através do uso de novos aspectos sobre um assunto. Os resultados obtidos 7possibilitaram o mapeamento dos obstáculos enfrentados na gestão dos $e$-books em unidades de informação. Por fim, as análises dos problemas devem contribuir para que as bibliotecas desenvolvam caminhos para melhorar os aspectos que se apresentam na configuração de um novo modelo informacional digital, contribuindo dessa forma, para o cumprimento da missão das bibliotecas de promover o acesso e incentivar o uso e a geração da informação em qualquer tipo de suporte.

PALAVRAS-CHAVE: E-books. Livros digitais. Bibliotecas universitárias.

\section{ABSTRACT}

The work addresses the challenges to expanding the use of e-books in Brazilian society, especially in university libraries. Through an investigation based on selection processes, acquisition, management and training of digital nature support collections seeks to offer a diagnosis objective about the obstacles faced to expand the use of e-books. It is intended to provide ways to democratize access, as well as the inventory of simplified procedures on the management of collections. One hopes that from the study, exposing procedures to facilitate the reduction of financial and human resources involving the use of e-books in libraries. From the reduction of costs and processes aimed to the improvement of products and services for the academic community. In this sense, this work is an important research for professionals in the Library and Information Science. The methodological approach applied was a literature review on the subject in the fields of Information Sciences, more specifically, of librarianship. This research model enables to expand the proportion of existing knowledge through the use of new aspects of a subject. The results enabled the mapping of obstacles encountered in the

\footnotetext{
1 Mestre em Biblioteconomia pela Universidade do Estado do Rio de Janeiro. Especialista em Gestão e Produção Cultural - UNESA. Rio de Janeiro, RJ, Brasil. https://orcid.org/0000-0002-5281-9179. E-mail: rdias100@hotmail.com
}

Submetido em: 15/01/2016 - Aceito em: 03/04/2016.

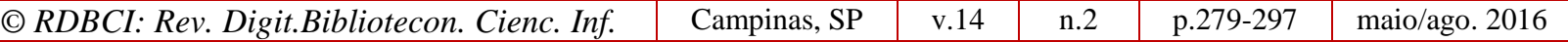


management of e-books in information units. Finally, the analysis of the problems should contribute to that libraries develop ways to improve the aspects that appear in the configuration of a new digital information model, thus contributing to the fulfillment of the mission of libraries to promote access and encourage the use and generating information on any type of support.

KEYWORDS: E-books. Digital books. University libraries.

\section{RESUMÉN}

El trabajo aborda los principales retos para ampliar el uso de los libros electrónicos en la sociedad brasileña, especialmente en las bibliotecas universitarias. A través de una investigación basada en los procesos de selección, adquisición, gestión y formación de la naturaleza colecciones de medios digitales busca ofrecer un diagnóstico objetivo sobre los obstáculos enfrentados para expandir el sudor de los libros electrónicos. Su objetivo es proporcionar los medios para democratizar el acceso, así como el inventario de procedimientos simplificados en la gestión de cobros. Apunta a partir de este estudio, la exposición de procedimientos para facilitar la reducción de los recursos financieros y humanos que involucran la gestión de libros electrónicos en las bibliotecas. de las reducciones en los costes del proceso y los objetivos para mejorar los productos y servicios ofrecidos a la comunidad académica. En este sentido, este trabajo es una investigación importante para los profesionales de la Biblioteca y Ciencias de la Información. el enfoque metodológico aplicado fue una revisión de la literatura sobre el tema propuesto en el ámbito de Ciencias de la Información, más específicamente, de la bibliotecología. Este modelo de investigación permite ampliar la proporción de los conocimientos existentes mediante el uso de nuevos aspectos de un sujeto. Los resultados permitieron a la cartografía de los obstáculos que enfrentan en la gestión de los libros electrónicos en las unidades de información. Por último, el análisis de los problemas que debe contribuir a que las bibliotecas se desarrollan formas de mejorar los aspectos que aparecen en la configuración de un nuevo modelo de información digital, lo que contribuye formas. Para cumplir la misión de las bibliotecas para promover el acceso y fomentar el uso y la generación de información sobre cualquier tipo de soporte.

PALABRAS CLAVE: e-libros. Libros digitales. Bibliotecas universitarias

\section{INTRODUÇÃ̃o}

Segundo Martins (2016) A história das bibliotecas mostra que no transcorrer da evolução da humanidade, as transformações nos suportes de registro do conhecimento fazem parte da trajetória da escrita e contribuem para o desenvolvimento do conhecimento, das ciências e do progresso humano. Nesse sentido, a utilização das tecnologias de informação e comunicação proporcionam alterações nos modelos de produção, comercialização e uso dos livros na sociedade contemporânea. Esses processos são modificados com a utilização da natureza digital e ocorrem mutações no modo de pensar e agir das bibliotecas que provoca um repensar da profissão bibliotecária. Os atuais profissionais devem estar propensos para novas possibilidades de atuação com a introdução dos e-books no contexto informacional. Esse suporte altera as formas de ação do profissional da informação, no tangente aos procedimentos que envolvem as relações com os outros atores do mercado editorial, principalmente, nas relações entre as bibliotecas e os fornecedores. Nesse sentido, a realização de debates sobre as formas de produção, comercialização e consumo da informação digital se fazem pertinente. $\mathrm{O}$ estudo das novas possibilidades oriundas das tecnologias se torna conexa e a avaliação dos modelos de negócios praticados pelo mercado se fazem essenciais para um projeto de expansão dessa natureza informacional nas bibliotecas 
universitárias.

A partir do aperfeiçoamento do diálogo entre os atores do mercado editorial, pode-se ocorrer melhora nos processos que circundam as atividades de formação de coleções digitais. Contudo, a contenda entre esses personagens está em fase de deliberação, onde os papéis estão sendo desenhados e as funções delimitadas. Nesse aspecto, ações que busquem a ampliação do debate em torno da melhora do uso dos e-books, nos diversos ambientes em que ele pode atuar, sejam nas bibliotecas, nas editoras, nos fornecedores, nos clientes etc... Devem ser desenvolvidas com o intuito de democratizar o acesso ao conteúdo informacional digital, bem como, melhorar o fluxo informacional da comunicação científica disponibilizada virtualmente por intermédio dessa natureza informacional.

As bibliotecas, os bibliotecários e os demais membros do mercado editorial necessitam procurar as melhores formas de gestão de acervos digitais, bem como as melhores práticas de comercialização dos modelos de negócios. É necessário o entendimento, por parte dos diversos atores desse mercado, que a ampliação das formas de acesso será benéfica para todos os envolvidos. Esse processo se torna importante, devido às peculiaridades envolvidas com a aquisição dos e-books. Enquanto suporte informacional digital, ele possui características gerais semelhantes aos materiais impressos e outras específicas de sua conjuntura digital. A partir desse entendimento, novas formas de pensar e planejar a seleção e aquisição, bem como, sua manutenção e acesso se tornam imprescindíveis para a área de formação e desenvolvimento de coleções. Diante das possibilidades oriundas da natureza informacional, compreende-se a necessidade de criação de mecanismos, políticas, parâmetros, diretrizes e ações para a formação e o desenvolvimento de coleções dessa natureza. Nesse cenário, sobressai o trabalho de Cunha (1999) que arrola os aspectos que devem ser destacados e pensados, em relação à seleção de objetos digitais, são eles:

- Variedade de formatos: o especialista em desenvolvimento de coleções necessita considerar os diversos formatos; Conceito de biblioteca: a biblioteca universitária não é apenas física, a tarefa de desenvolvimento de coleções incluirá funções relativas às atividades de hiperligações para mapear os recursos informacionais externos;

- $\quad$ Pagamento pela informação: será necessário conhecer os detalhes relativos às modalidades de contratação para acessar a informação, ou seja, os processos que envolvem os negócios se tornam de extrema importância para a área de formação de coleções;

- Esforços cooperativos: com o objetivo de reduzir os custos da duplicação de acervos eletrônicos, em diversas universidades, haverá campo propício para ações cooperativas mediante convênios; a coleção local não será mais o foco primário de atenção, o mesmo objeto deverá ser acessado por todos e;

- Novas mídias e equipamentos: para otimizar o uso do documento digital será necessário maior conhecimento de hardware e software por parte dos técnicos de desenvolvimento de coleções. 


\section{MÉTODO}

A metodologia aplicada foi a revisão de literatura acerca do tema e-books e seus obstáculos, o estudo aconteceu nos campos das Ciências da Informação, mais especificamente, da Biblioteconomia. Esse modelo de pesquisa possibilita ampliar a proporção do conhecimento existente através do uso de novos aspectos sobre um assunto. Foram estudados livros, artigos de periódicos, dissertações, teses, trabalhos apresentados em eventos e congressos, bem como, sites especializados nas áreas de Biblioteconomia e Administração. A pesquisa foi realizada na plataforma Descubra, da Universidade do Estado do Rio de Janeiro (UERJ) que abrange diversas bases de dados. Foram pesquisadas também, as bases de dados Science Direct, EBSCP, Wiley, Emerald, BRAPCI, Scielo e E-lis. Foram investigados termos em inglês e português, nos campos títulos (titles), palavras-chave (keywords) e resumo (abstracts) tanto na literatura nacional com internacional. Optou-se por trabalhos escritos a partir dos anos 2000. Contudo, devido à importância histórica foram considerados trabalhos clássicos anteriores. Os resultados obtidos possibilitaram 0 mapeamento dos obstáculos encontrados na gestão dos e-books.

\section{DESENVOLVIMENTO DE COLEÇÕES PARA E-BOOKS}

A International Federation of Library Associations and Institutions (IFLA, 2013), elaborou um guia para as bibliotecas acadêmicas, especialmente, destinado às coleções de recursos eletrônicos. Ele tem o intuito de conscientizar sobre os pontos principais que as bibliotecas deverão considerar para formação das coleções eletrônicas onde são destacados os principais pontos:

- Viabilidade técnica: disponibilidade (acesso remoto, acesso autônomo), autenticação, compatibilidade, armazenamento e manutenção (acesso remoto, acesso local), plataformas de acesso aos recursos eletrônicos;

- Funcionalidade e confiabilidade: recuperação da informação, descarga de conteúdo, exportação e descarga, interface, integração;

- Apoio do provedor: capacitação dos usuários, demonstração de produtos, suporte técnico, relatório de estatística, Personalização do serviço, provisão de dados bibliográficos (Marc), segurança da informação e política de armazenamento;

- Fornecimento: modelo de compra (assinatura ou pago por consulta), opções de acesso, armazenamento, cotas de manutenção e direitos de cancelamento e;

- Licenças: licenças, modelo padrão, legislação vigente, responsabilidade pelo uso não autorizado, definição de usuários autorizados, definição de sítios autorizados, reembolsos, prazo do contrato, idioma de licença, cumprimento com as leis vigentes na jurisdição que se encontra a biblioteca, caso seja um consórcio.

Os aspectos apresentados referem-se aos recursos digitais de uma maneira geral. Contudo, entende-se que cada objeto digital possui especificidades de sua natureza. Nesse 
sentido, é fundamental a criação de políticas especificas para $o$ e-book. Pontes (2015) aborda a aquisição dos livros digitais para bibliotecas universitárias e relata que existe a necessidade de criação de uma política institucional especifica para a natureza informacional digital que deve contemplar os seguintes aspectos:

- Direitos de licenciamento - questão da exclusividade;

- $\quad$ Preservação de conteúdos digitais;

- $\quad$ Formas de acesso;

- Modelos de negócios / contratação;

- $\quad$ Formatos de registro (pdf. E-pub. Mobi. Azw ...);

- Mediação com uso de dispositivos específicos (e-readers, tablets);

- $\quad$ Controle de uso (indicadores);

- $\quad$ Forma de entrega e e-lending (GRM - DRM);

- Instituições públicas devem seguir a legislação n. 8.666/1993;

- Capacitação de gestão de vários contratos;

- Recursos institucionais para disponibilização e preservação do acervo digital;

- Orçamento disponível para aquisição e;

- Vantagens institucionais para a aquisição de acervo digital.

Cunha (1999), IFLA (2013) e Pontes (2015) consideram a necessidade de aperfeiçoamento das bibliotecas na criação de políticas para expansão da natureza digital nas unidades de informação. Nesse sentido, apresentam os seguintes tópicos que devem ser analisados pelos bibliotecários.

Estudos de usuários traçando o perfil do público real, potencial e virtual. Incluindo os alunos de estudo à distância; diagnóstico do cenário em que a biblioteca está inserida. Devem-se verificar aspectos geográficos, sociais, econômicos e tecnológicos; busca contínua em suprir as expectativas e as necessidades dos clientes da informação, independentemente da localização da informação ou do cliente; diagnóstico e descrição dos fornecedores disponíveis no mercado. Analisando as vantagens e as desvantagens competitivas que cada um apresenta; planejamento orçamentário com previsão para gastos atuais e futuros, deve-se formalizar as fontes de recursos disponíveis e as formas de pagamentos para manutenção das coleções. Destacam a importância de adquirir e mantê-las, tanto as impressas como as digitais; racionalização e otimização dos recursos financeiros, humanos e tecnológicos; descrição completa das bases e averiguação da disponibilidade de customização; descrição dos modelos de negócios, apresentando as vantagens e desvantagens de cada padrão; criação de política de acesso e acessibilidade, contemplando acesso multiusuário e formas de promoção aos portadores de necessidades especiais; elaboração de planos de ação em relação à seleção, aquisição, descarte, desbaste e avaliações futuras, das coleções existentes, novas e passíveis de obtenção; respeito às especificidades e especificações de cada natureza informacional; estabelecimento da obrigação do fornecimento de metadados para recursos eletrônicos; criação de mecanismos e ferramentas para controlar a explosão bibliográfica impressa e digital nas bibliotecas; concepção de mecanismos para avaliar pontos fortes e fracos das coleções através do uso de medidas objetivas de julgamento; racionalização do 
espaço físico e tecnológico; compartilhamento de recursos e estabelecimento de consórcios/redes de trabalho; formalização de mecanismos e critérios para intercâmbio de materiais informacionais físicos e digitais; estabelecimento de mecanismos para preservação das coleções físicas e digitais; descrição das formas de backup: mídia fixa ou backfile; acompanhamento do surgimento de novos suportes de informação, não se limitando aos suportes existentes e respeito à legislação vigente no país.

Esses predicados buscam atender as demandas das bibliotecas, na atualidade, através da concretização de parâmetros para aquisição dos e-books. Pretende-se dessa forma, formar coleções que satisfaçam as necessidades dos clientes. Almeja-se, a construção de acervos de qualidade que contribuam para o desenvolvimento das pesquisas e auxiliem na transferência da comunicação científica nas universidades. Nesse contexto, a política de formação e desenvolvimento de coleções para e-books deve contemplar procedimentos políticos, tecnológicos, de gerenciamento dos conteúdos, recursos e acesso, necessita ainda, abarcar questões relacionadas com o design de produtos, abranger motes arrolados com a proteção aos direitos autorais e a propriedade intelectual. Além disso, precisa determinar as formas de suporte e os responsáveis por sua aplicação. Por fim, requer normas de preservação dos objetos virtuais. Para concretização dessa política é imprescindível à realização de planejamento a curto, médio e longo prazo dos procedimentos necessários para sua concepção. Nele devem constar ações para sua consecução verificando as previsões orçamentárias, a organização, distribuição, estruturação, compartilhamento, parque tecnológico, bem como, os responsáveis pelas tarefas. Além disso, é fundamental o conhecimento do mercado editorial, dos atores da cadeia produtiva dos livros e dos modelos de negócios nacionais e internacionais. Essa política deve servir como um guia ou suporte para bibliotecários, auxiliando para a tomada de decisão na aquisição de objetos virtuais. Nesse contexto, ela busca melhorar as práticas de trabalho, buscando aprimorar as afinidades entre os atores do mercado editorial. Contudo, conforme citam Martins e Scarvarda (2015) "os critérios tradicionais de desenvolvimento de coleção estão sendo usados na aplicação de seleção e aquisição de recursos eletrônicos”, o que gera inúmeros desperdícios para as bibliotecas e dificuldades para acesso as informações por parte dos usuários. Dessa forma, a formação e o desenvolvimento de objetos em formato digital necessitam de novas formas de ação, com o estabelecimento de procedimentos específicos para esse modelo de suporte. Pensamento semelhante aos de White e Crawford (1997), que entendem que os mesmos elementos que permeiam uma política tradicional devam servir para os documentos eletrônicos, tais como:

a) finalidade, missão e os objetivos da instituição; b) o nível de desenvolvimento de coleções, bem como as responsabilidades; c) a comunidade visada; d) os pontos fortes e fracos da coleção; e) a justificativa dos critérios de seleção e avaliação; f) as condições de desbastamento e de cooperação com as outras bibliotecas.

Entretanto, acredita-se que novas demandas surgirão na área de desenvolvimento de coleções, com o uso das coleções eletrônicas e virtuais. Assim, outras ações serão pertinentes para a formação de coleções. 


\section{DIFICULDADES PARA EXPANSÃo DOS E-BOOKS}

A caminhada para a expansão dos e-books na sociedade brasileira possui implicações que necessitam de aperfeiçoamento. É importante diagnosticar os entraves existentes com o intuito de traçar um plano para solucioná-los. Elas possuem origens variadas e carecem de um pacto entre autores, editores, bibliotecários, professores, governo e cidadãos para que sejam sanados. Entende-se que os problemas possuem enfoques ligados as áreas de educação, tecnologias, administração, gestão, telecomunicações, aspectos sociais e econômicos do país. Percebe-se que às dificuldades de expansão dos e-books em nossa sociedade possui relação com a com a falta de uma política governamental sobre o objeto. Nesse sentido, fica evidente a necessidade de aperfeiçoamento do arcabouço que envolve o gerenciamento da informação digital. Dessa forma, é fundamental o debate e a discussão de propostas para melhorar a estrutura física, logística, tecnológica, de telecomunicações, orçamentária e de recursos humanos que envolvem a aquisição dos e-books. Assim sendo, devem-se estudar as estruturas que abrangem a aquisição dos livros digitais, optando-se pela aquisição centralizada, compartilhada ao invés da compra isolada. Além disso, devem ser criados novos parâmetros para a seleção e a aquisição. Ademais, o processo de formação e de desenvolvimento de coleções aplicado pelas bibliotecas universitárias requer novos dimensionamentos. As formas igualitárias utilizadas pelas unidades de informação para documentos impressos e digitais inibem as possibilidades e oportunidades oriundas da natureza digital. Isso ocorre, principalmente, devido ao uso dos mesmos modelos clássicos e tradicionais, utilizados durante décadas para seleção, aquisição e gerenciamento de livros impressos aplicados por todo o mercado editorial aos objetos digitais. Além disso, percebem-se dificuldades relacionadas ao processo de comercialização dos e-books entre editores e bibliotecários. Não há consenso entre as partes e as limitações impostas nos negócios provocam barreiras para o acesso à informação. Nesse cenário, tanto os livros impressos como os digitais são adquiridos, gerenciados, usados e transmitidos da mesma forma. Isso demonstra instabilidade na forma de geri-los, contribuindo dessa forma, para inibir a expansão e a democratização desse suporte informacional. Assim sendo, percebe-se que a inexistência de um projeto de aquisição específico para obras digitais é um fator que prejudica sua expansão e seu uso na sociedade e, mais especificamente, nas bibliotecas. Essas ressalvas contribuem para os baixos investimentos na compra de livros digitais; os custos elevados para aquisição; a compra dos mesmos títulos; a demora nas entregas e a insatisfação dos clientes. Igualmente a exposição desses problemas, compreende-se incertezas que abarcam os bibliotecários, principalmente, nos aspectos relacionados com os negócios digitais. Nesse seguimento, inúmeras incógnitas circundam os profissionais da informação referente ao processo de formação e desenvolvimento de coleções digitais. Assim, os principais questionamentos desses profissionais são apresentados na literatura nacional e internacional e destacados no trabalho de Martins (2016) são relacionados abaixo:

- Quais as possibilidades oriundas da natureza informacional digital?

- $\quad$ Porque comprar e-books?

- Como comprar?

- Quais os modelos de negócios existentes?

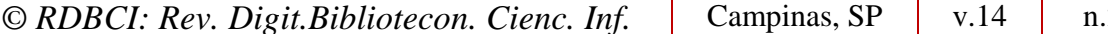

p.279-297

maio/ago. 2016 
- Quais as diferenças entre os modelos?

- Esses modelos facilitam ou dificultam o acesso?

- Como os clientes irão acessar a informação?

- Quais os aparelhos eletrônicos que as bibliotecas necessitam adquirir?

- Quais os formatos existentes?

- Quais as diferenças entre os formatos?

- O que é permitido acessar?

- $\quad$ O que se pode fazer em relação aos conteúdos?

- Quantos podem ler ao mesmo tempo?

- Quais as vantagens oriundas da aquisição de livros digitais?

- Quais as dificuldades na relação biblioteca, editores, clientes em relação aos e-books?

- O que é DRM?

- Como emprestar esse suporte informacional?

- $\quad \mathrm{O}$ acesso é restrito ou remoto?

- Como catalogar os itens?

- Como inserir nos catálogos das bibliotecas?

- Como realizar as estatísticas de uso?

- O que fazer com as doações?

- Quais os parâmetros para avaliar o acervo digital?

- $\quad$ Existe descarte e/ou desbaste?

- Como realizar empréstimo entre bibliotecas?

- Quais são as formas de atualização?

- Quais as formas legais que envolvem a aquisição e o uso? e;

- Como proteger os direitos autorais e a propriedade intelectual dos atores que envolvem a concepção dos e-books?

Essas são algumas questões, observadas e identificadas no processo de construção desse trabalho, que dificultam a expansão do suporte digital nas bibliotecas universitárias. Elas contemplam inquietudes dos bibliotecários em relação aos processos que envolvem a seleção, aquisição, gerenciamento, aspectos legais e uso dos livros digitais. Além das dificuldades apresentadas no arrolar desse estudo, verificamos que " $42 \%$ das unidades de informação não possuem os e-books em seus acervos” (LIMA, FELDMAN; JULIANI, 2015), ou seja, quase metade das bibliotecas universitárias públicas brasileiras não oferece esse produto aos seus clientes. Essa constatação demonstra um prejuízo na disseminação do conhecimento cientifico e, consequentemente, atrasa o desenvolvimento econômico, social e cultural da nação. Nos próximos tópicos serão esmiuçadas as principais barreiras enfrentadas para a expansão dos livros digitais na sociedade brasileira.

\subsection{Modelos de negócios inviáveis na contemporaneidade}

Em relação à administração e gestão dos e-books, entende-se que os modelos de negócios aplicados pelo mercado editorial possuem imposição dos editores frente às bibliotecas. Barros (2013) reafirma esse pensamento e relata "o maior problema que existe na 
adoção de $e$-books diz respeito aos contratos estabelecidos entre os editores/fornecedores e as bibliotecas". Silva (2013) aborda o assunto retratando a obrigação da compra em pacotes fechados. Ele diz "a principal desvantagem na relação das bibliotecas com os editores está no fato de que a compra dos e-books requer a aquisição de pacotes de dados completos de um grupo de poucas editoras”. Dessa forma, compram-se vários livros e, apenas uma pequena parcela é utilizada. Barros (2013) afirma que as plataformas de fornecedores proporcionam o acesso a uma grande quantidade de conteúdo, enquanto liberam as bibliotecas da complexidade da negociação junto às editoras. Contudo, "condições restritivas e a incerteza sobre a posse do conteúdo minam a capacidade das bibliotecas de gerenciar as coleções digitais a sua maneira" (BARROS, 2013). Além disso, verificam-se barreiras para a seleção dos títulos. Enquanto no modelo impresso, os bibliotecários exerciam a tarefa de selecionar os materiais que seriam incorporados aos acervos, no modelo virtual essa prática tem sido realizada pelos editores, através de seus pacotes determinados. Nesse sentido, observa-se a decadência da qualidade das coleções, ou seja, no modelo digital vem ocorrendo uma diferença entre as expectativas das bibliotecas e a oferta dos editores. O panorama apresenta uma reconfiguração do papel dos bibliotecários na área de seleção. Enquanto, anteriormente, ele exercia a função pick and choose (selecionar título a título) onde são selecionados os materiais que as bibliotecas desejam, baseados em critérios estabelecidos na política de desenvolvimento de coleções, aonde se busca cobrir as necessidades mais imediatas dos usuários. Nessa configuração, existem esforços maiores na seleção. Contudo, obtêm-se materiais com maior rigidez e qualidade, evitando assim, desperdício de recursos financeiros e humanos. No padrão proposto pelos editores, onde ocorre a venda em pacote, há uma tendência para a renúncia ao processo de formação e desenvolvimento de coleções, mais especificamente da seleção de materiais. Nesse cenário, o bibliotecário perde o poder de selecionar as obras a serem inseridas nos acervos, adquirindo livros de qualidade duvidosa. Independente do modelo seguido pela biblioteca verifica-se que o mercado de vendas de $e$ books ainda está em processo de formação e definição. É fundamental que seja solucionado o "duelo" entre editores x bibliotecários, referente às possibilidades dos livros digitais. Enquanto as bibliotecas defendem a questão da pluralidade de acessos, os editores protegem a salvaguarda dos negócios. Assim sendo, é necessário o debate sobre os seguintes predicados: A ampliação de acessos multiusuários é uma demanda latente das bibliotecas. Contudo, os editores evitam a todo custo o aumento dos acessos nas unidades de informação. Eles temem que essa facilidade provoque redução na venda dos e-books. Entretanto, considera-se que o aumento da divulgação de livros digitais nas bibliotecas possibilite a difusão das obras e proporcionem o aumento das vendas e; o empréstimo dos e-books entre bibliotecas é um pleito do mercado biblioteconômico. O aumento de empréstimos e circulação proporciona a efetiva difusão dos livros digitais. Com isso, tende-se para ampliação do uso dos objetos digitais e esse aumento deve favorecer os editores, as bibliotecas e os clientes da informação.

\subsection{Aquisição aleatória}

Atualmente, devido à carência de uniformidade do mercado editorial digital, as bibliotecas universitárias realizam a aquisição dos e-books de forma aleatória, sem a

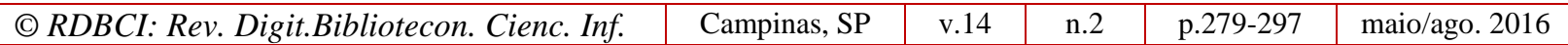


padronização necessária dos processos e com inúmeras barreiras protecionistas estipuladas pelos fornecedores. Isso ocasiona má formação de acervos; ausência coletiva de negociações; gastos excessivos (tanto para as unidades informacionais como para o governo); comportamento de compras repetidas de títulos; aquisição de pacotes pré-determinados pelos fornecedores com qualidade duvidosa; ausência ou insuficiência do processo de formação e desenvolvimento de coleções digitais pelos bibliotecários e dificuldades para acessar e utilizar os livros digitais. Esses fatores são responsáveis pela formação de acervos de baixa qualidade, com pouca rotatividade (de consultas e empréstimos) e impossibilita a livre circulação da informação devido às restrições impostas. Diante desse panorama, é fundamental a revisão dos modelos de negócios existentes, buscando-se a compra conjunta e centralizada. Ela visa a expansão do uso dos e-books nas unidades de informação através da redução dos custos com a compra de livros digitais. Isso é possibilitado devido a aquisição concentrada em grandes volumes de itens que devem gerar qualidade aos produtos adquiridos; redução dos processos repetidos; diminuição de recursos humanos para realização das tarefas; melhora no planejamento das ações, criação de logística de distribuição; uniformização dos procedimentos; padronização dos bens e serviços contratados; facilidades para manutenção e uso dos e-books. A aquisição conjunta de acervos digitais envolve aporte financeiro governamental e criação de política de governo para criação de uma ferramenta, gerencial e estratégica, de gestão dos e-books.

\subsection{Estagnação financeira}

Compreende-se que a estagnação da economia mundial, em especial, no Brasil; aliada aos problemas sociais e econômicos provocados pelas crises globais que intensificam as desigualdades de renda; em conjunto com o crescimento do desemprego; os baixos salários; o aumento da miséria e as constantes crises políticas apresentam-se como obstáculos para a ampliação do uso dos e-books em todas as camadas da população. Dessa forma, é fundamental que o país se realinhe no caminho do desenvolvimento econômico. Entende-se, que além dos problemas relacionados com a imposição do mercado em aplicar modelos desvantajosos para as unidades informacionais. Além das taxas de compra, das licenças de uso, dos servidores necessários para suporte tecnológico, dos recursos físicos, tecnológicos e humanos ainda temos, em alguns casos, necessidade de aquisição de aparelhos tecnológicos para disponibilizar aos usuários. Barros (2013) corrobora esses fatores relatando que "existem os pagamentos de taxas anuais, necessidade de aparelhos tecnológicos e constantes mudanças oriundas do desgaste ou dos avanços tecnológicos". Além disso, existe a preocupação com gastos relacionados com a preservação dos dados, bem como, com o pessoal necessário para trabalhar com esse modelo de suporte informacional. Nesse sentido, Vergueiro (1997) relata que "a definição dos custos da informação obtida por intermédio de redes eletrônicas ainda é mais ou menos incerta". O autor ainda especula "será possível às bibliotecas manterem indefinidamente a prática de não-cobrança direta ao cliente, quando da utilização de meios eletrônicos", ou seja, será possível que as bibliotecas mantenham o acesso ao conteúdo informacional gratuito ou haverá necessidade de cobrança por esse serviço? Essa questão é oportuna ao avaliar os altos custos envolvidos na obtenção de informação em objetos digitais.

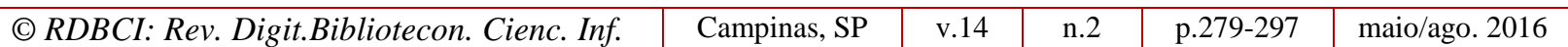


Contudo, percebe-se que as bibliotecas precisam estar atentas para essas questões e precisam trabalhar com planejamento estratégico e orçamentário. Dessa forma, essas dificuldades poderão ser reduzidas.

\subsection{Impedimentos tecnológicos e de telecomunicações}

Anuradha e Usha (2006), apresentam possíveis razões que dificultam a popularização dos e-books no Brasil. Dentre elas, destacam-se os problemas relacionados com os aparatos tecnológicos e as telecomunicações necessárias para acessar a internet. Para os autores existem problemas, tanto nas redes físicas como nas redes móveis. Para eles, uma grande dificuldade enfrentada atualmente tem ligação com "a falta de padronização nos hardwares e softwares". A inexistência de padrões atrapalha a escolha dos equipamentos de leitura provocando o desestímulo ao uso dos e-books. Procópio (2013) relata as dificuldades relacionadas com as telecomunicações no Brasil. Para ele "existem obstáculos ao acesso à internet em várias partes do país. Esse problema é verificado nas regiões norte e nordeste do Brasil, nas zonas rurais e nos subúrbios das grandes cidades". Outro problema verificado está no acesso remoto, a utilização de equipamentos portáteis, principalmente, os aparelhos celulares facilitam a difusão do conhecimento humano. Afinal, grande parcela da população utiliza os smartphones como meio para leitura. Contudo, para isso ocorra de fato é fundamental a melhora na conexão remota, tanto em velocidade como em qualidade. (PROCOPIO, 2013).

\subsection{Barreiras culturais}

Bonezi (2007) apresenta aspecto sensorial e cultural como obstáculo ao desenvolvimento dos e-books. Ele relata que "a perda da sensação física proporcionada pelo livro tradicional é uma das principais queixas dos leitores" o que torna a leitura mais lenta e cansativa. Além disso, "grande parte das pessoas ainda preferem a leitura no papel ao invés de ler em uma cansativa tela de cristal líquido, que é utilizada nos computadores e aparelhos portáteis" (BONEZI, 2007). Ventura (2000) aborda a questão como "perda da sensação física do livro". Para ela, "não haverá possibilidade de folheamento ou apreciação do livro no momento da compra" e complementa questionando sobre as dedicatórias e os autógrafos? O lançamento de livro eletrônico? A forma de presentear alguém? (VENTURA, 2000).

O hábito enraizado de leitura em papel, que durante séculos fez parte da natureza humana, tem sido um empecilho, principalmente, nos leitores mais tradicionais. Contudo, percebem-se ações dos fabricantes de leitores de e-books para uma melhora, significativa, nos equipamentos que servem para leitura da natureza informacional digital. As versões modernas, cada vez mais, se aproximam da sensação de leitura em materiais impressos.

\subsection{Barreiras para os leitores}

Duarte (2007) apresenta dificuldades para os leitores na aquisição dos e-books. Para ela, existe o "medo" de comprar materiais falsificados e, dessa forma, realizar downloads

\begin{tabular}{|c|c|c|c|c|c|}
\hline (C) RDBCI: Rev. Digit.Bibliotecon. Cienc. Inf. & Campinas, SP & v. 14 & 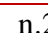 & p. 279-297 & \\
\hline
\end{tabular}


ilegais. Além disso, ela elenca os seguintes obstáculos: "a questão do custo (manipulação de cartões de crédito para pagamentos de e-readers, e-books e assinaturas; preço elevado; preço com a manutenção de dispositivos" Outro fator que dificulta a expansão dos e-books relacionada aos leitores tem relação com a exclusão digital. Nesse aspecto, Diniz (2002) aborda a questão tratando-a como "um fenômeno que impossibilita a utilização dos serviços oferecidos através de canais eletrônicos resultante da dificuldade, por motivos sociais ou econômicos, de acesso às tecnologias básicas que permitam a conexão com o universo digital.

Scalco (2012) complementa relatando que a ONU, inclusive, declarou o acesso à internet como um direito universal, por entender que o acesso à rede facilita outros direitos econômicos, sociais, políticos e culturais, tornando-se uma ferramenta essencial para o acesso à informação, a fim de promover a participação dos cidadãos na construção de sociedades democráticas, uma vez que viabiliza a mobilização da população para expressar-se e comunicar-se.

\subsection{Problemas relacionados com os autores}

Segundo Melo (2012) "aos autores, cabe o desafio de adaptação do processo de criação de conteúdo informacional ao novo universo digital". Para o autor "eles dispõem de novas possibilidades de expressão e transmissão de ideias por meio de novas ferramentas de trabalho". Assim, os processos editoriais precisam de reordenamento e reenquadramento para que possam gerar novos produtos. Contudo, para que isso se torne possível o aprendizado em realizar novas tarefas e funções deve fazer parte do cotidiano de autores e editores. $\mathrm{O}$ aprendizado das novas metodologias de criação de livros é primordial para a sobrevivência dos autores nesse novo mercado editorial. Melo (2012) relata que "se projeta uma mudança radical no processo de construção dos e-books, onde o conteúdo final da versão impressa, quando houver, será definido depois da concepção do livro digital”, ou seja, depois da exploração dos recursos e possibilidades adicionais exclusivas da versão digital. O livro impresso, em muitos casos, passará a ser um produto derivado de um novo produto, o livro digital (MELO, 2012). Assim sendo, a concepção do livro digital transcende ao produto escrito, ele é dinâmico, multimídia, com inúmeras possibilidades de acesso as informações em variados tipos de mídias ao mesmo tempo. Dessa forma, aos autores cabe a realização de trabalho em conjunto com profissionais de outras áreas, tais como: design, tecnologia da informação, eletrônica e informática. Assim sendo, a produção de e-books será realizada através da coprodução de profissionais distintos utilizando diversas mídias. Tornando o processo de concepção de livros em projetos que envolvem diversos atores. Dentre eles haverá o responsável pelo conteúdo informacional escrito, sonoro, visual, midiático e outras formas que surgirão no futuro. Provavelmente, teremos obras inimagináveis na literatura mundial. A partir dessas obras poderemos alcançar avanços consideráveis nas ciências e, possivelmente, teremos melhorias, significativas, na sociedade. Aos autores existem problemas relacionados com os direitos autorais e a propriedade intelectual de suas obras. Essa questão tem sido debatida em todo o mundo. No Brasil, há uma preocupação grande com essa questão que é abordada na lei $\mathrm{n}^{\circ} 9.610$ de 1998, que trata do assunto e tenta regular

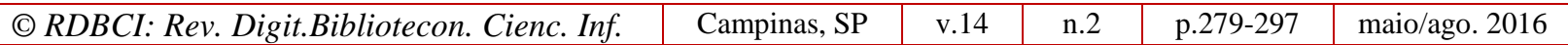


o direito autoral e os seus conexos. A preocupação com questões relacionadas aos direitos autorais ocorre devido às facilidades proporcionadas pelas tecnologias da informação e comunicação. Ela possibilita a ampliação da pirataria digital em escalas avassaladoras, o que gera prejuízos incalculáveis aos autores. Assim, há uma grande inquietação dos escritores em relação às questões das cópias não autorizadas. Para os autores, ainda há obstáculos em relação à auto publicação que ainda está em fase de implantação. Existem poucas opções de hardware/software disponíveis no mercado e, ainda, é necessário treinamento para que o escritor produza, publique, divulgue e venda seus livros.

\subsection{Inexistência de programa governamental de incentivo ao uso dos e-books}

A leitura proporciona a ampliação da capacidade de escrita, argumentação, gramatica, vocabulário e poder crítico do indivíduo e deve ser uma prioridade nas políticas governamentais. Nesse contexto, é fundamental a criação de programas de apoio ao hábito da leitura digital que devem colaborar para o desenvolvimento dos cidadãos $\mathrm{e}$, consequentemente, da nação. Para que isso ocorra, são necessários planos de governo, com o objetivo do fortalecimento da educação, a fim do aprimoramento das práticas de leitura nas crianças, jovens e adultos. Além disso, é primordial uma atualização das práticas pedagógicas nas universidades brasileiras, onde a introdução dos e-books se façam presentes nas atividades curriculares. Os problemas provenientes da falta de programas governamentais de apoio à leitura digital possuem inúmeras causas e podem ser caracterizados da seguinte forma:

- Baixa escolaridade da população;

- Inexistência de política governamental de incentivo à leitura digital nas escolas, principalmente, nas de ensino fundamental;

- Ausência do hábito da leitura digital nas crianças, jovens e adultos originários de problemas de ordem social e financeira que colabora para a redução da leitura dos e-books;

- Inexistência de trabalho conjunto entre bibliotecários e professores na construção de campanhas de uso de e-books;

- Maior participação das bibliotecas universitárias em ações de incentivo à leitura digital;

- Falta de comunicação com os alunos para saber suas necessidades informacionais digitais.

\subsection{Ausência da participação dos professores}

Para que os e-books se expandam no país, é primordial a participação dos professores no processo de difusão do conhecimento. É necessário que haja uma conexão entre os professores e a biblioteca com o objetivo de formação de leitores digitais. Para tanto, é essencial que um projeto pedagógico que englobe as naturezas digitais na formação dos alunos. Esse projeto deve ser elaborado pelos professores, pedagogos, bibliotecários e 
analistas de sistemas com o intuito de construção de um arcabouço para expansão da prática de ensino e leitura nas plataformas eletrônicas. Para tanto, são necessárias condições materiais, físicas, tecnológicas e recursos humanos para o cumprimento dessa árdua tarefa. Assim sendo, o maciço investimento na educação é premissa básica para que os $e$-books se tornem um elemento importante de difusão do conhecimento na sociedade. Contudo, percebe-se que os investimentos públicos em educação e, consequentemente, nos projetos que envolvem os e-books são insuficientes para atender com qualidade as necessidades da sociedade.

\subsection{Digital Rights Management}

Existem inúmeras definições para Digital Rights Management (Gestão de direitos digitais, em português). Existem definições que apoiam seu uso e outras contrárias. Os defensores do uso do DRM acreditam que a falta de uma resposta editorial "legal" faz com que a prática da pirataria se torne um hábito entre os leitores (ALONSO-ARÉVALO; CORDON GARCIA, 2010). Nesse sentido, podemos considerar que o "hábito" em baixar livros digitais de forma ilegal, pode provocar redução nas consultas e empréstimos nas bibliotecas. Assim, pode ocorrer diminuição de vendas para os editores. Afinal, é mais fácil e rápido baixar os livros da internet. Além disso, a utilização de DRM garante a proteção aos direitos autorais no modelo de difusão do conhecimento digital. Ianzen; Pinto e Wildaur (2013) definem DRM como "sistemas que primam pela tentativa de prevenir o uso indevido de determinados arquivos eletrônicos". De acordo com Pinheiro e Sleiman (2009) ele "visa garantir a confidencialidade, a autenticidade, a integridade e a disponibilidade das informações". Segundo Dziekaniak (2010), "as tecnologias envolvidas nesses softwares prometem intimidar a pirataria e guardar todos os direitos sobre um documento eletrônico", ou seja, a DRM tem o intuito de reduzir os "perigos eminentes do mercado". Assim sendo, os contratos firmados entre os editores e as bibliotecas são embutidos por inúmeras questões de salvaguarda de acesso. Pode-se considerar, na visão dos defensores da DRM que a proteção dos direitos autorais é realizada através de ferramentas que tentam preservar as formas de acesso aos documentos e sua utilização ocorre a partir de sistemas que combinam hardwares e softwares que criptografam as obras, permitindo, normalmente, apenas a leitura de seu conteúdo. (ALONSO-ARÉVALO; CORDON GARCIA, 2010). Pretende-se dessa forma, prevenir a duplicação não autorizada de trabalhos e garantir a manutenção da integridade das obras.

Há também a existência de movimentos contrários ao uso do DRM, sendo, inclusive chamado de "Digital Restrictions Management", já que afeta negativamente os softwares livres. (IANZEN; PINTO E WILDAUR, 2013). De acordo com Melo (2011) a utilização de DRM não impede a pirataria dos e-books. Afinal, "a criptografia do DRM é quebrada por hackers, mais cedo ou mais tarde, como foi o caso do kindle". Mello (2011) afirma que o DRM "impede, isso sim, são os usos honestos do e-book por aquele leitor ou leitora que é, afinal de contas, honesto". Nesse panorama, os usuários ficam impedidos de realizar qualquer prática de liberdade de ação. Além disso, percebe-se problemas com os DRMs de livros que são lidos em uma única plataforma de fornecedor/editor de conteúdo e casos em que os

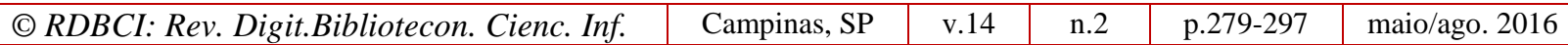


DRMs não são convertidos para tecnologia futuras, ou seja, e-books adquiridos hoje, de forma legal, poderão perder o acesso daqui há alguns, poucos, anos. Assim sendo, percebe-se que a utilização do DRM contribui para o esvaziamento dos $e$-books como prática de leitura. O problema é que o DRM não serve somente para impedir a circulação livre do conteúdo eletrônico que sai das editoras, ou para proteger e-books e arquivos eletrônicos contra usos não autorizados. Serve também para controlar como, quando e onde um determinado leitor poderá ler determinado $e$-book, colocando a experiência da leitura à mercê do que decidem vendedores, editoras e distribuidores on-line - quando essas decisões devem estar nas mãos dos leitores que compram os livros. (MELO, 2011).

Os opositores ao uso de DRM garantem que essa proteção visa garantir maiores receitas para as editoras. De acordo com Marreiros (2007) "é sabido, trata-se antes de proteger a sua fonte de receitas, simultaneamente melhorando e alargando essas mesmas fontes", o autor segue tratando do tema como "uma solução tecnicamente muito boa, com todos os meios de segurança para a distribuição e consumo de conteúdos sobre diferentes plataformas e dispositivos", adiante relata É um modelo de negócio agressivo, mostrando claramente como o operador pode maximizar a rentabilidade dos conteúdos que recebe, mantendo-lhe aberta a possibilidade de adquirir/licenciar mais conteúdos dos fornecedores, e assim gerando também mais receitas para estes. (MARREIROS, 2007).

De acordo com o IDEC; CENTRO DE TECNOLOGIA E SOCIEDADE; FGV DIREITO RIO (2007) apud Ianzen; Pinto e Wildaur (2013) “é imprescindível a busca por um equilíbrio entre a legítima remuneração dos criadores e a necessidade da democratização da tecnologia e do acesso ao conhecimento". Contudo, esses autores consideram não se justificar "o abuso na utilização das restrições tecnológicas, sem respeitar os interesses dos consumidores, a realidade tecnológica e até mesmo os direitos de utilização concedidos à sociedade pela legislação de direito autoral". Por fim, apresenta-se a questão da interoperabilidade de sistemas que é afetado diretamente pela DRM. Nesse sentido, Marreiros (2007) cita "um dos maiores problemas com que a indústria se depara relativamente ao tema DRM, é de fato como obter interoperabilidade entre diversos dispositivos se estes usarem diferentes sistemas de DRM".

\subsection{Dificuldades para as bibliotecas}

Compreende-se que algumas dificuldades enfrentadas pelas unidades de informação são as mesmas apresentadas anteriormente em outras questões analisadas. Contudo, precisamos enfocar alguns tópicos que se apresentam da seguinte forma: altos custos iniciais com a compra de softwares, hardwares e servidores conforme relata Barros (2013). Além da melhoria no parque tecnológico são necessários avanços e progressos nas redes de telecomunicações e elétrica. É fundamental ainda, o compromisso orçamentário para manutenção dos acervos, atualização de equipamentos, migrações futuras, preservação digital de dados e custos com recursos humanos. A criação de uma política especifica para desenvolvimento de coleções digitais é fundamental para a formação de acervos de qualidade e fácil acesso. Nesse sentido, deve-se elaborar estudo de usuários e de uso para a obtenção de materiais de utilidade. Dessa forma, a concepção de critérios para avaliação se tornam

\begin{tabular}{|c|c|c|c|c|c|}
\hline (C) RDBCI: Rev. Digit.Bibliotecon. Cienc. Inf. & Campinas, SP & v.14 & $\mathrm{n} .2$ & 2 279-297 & maio/ago 2016 \\
\hline
\end{tabular}


necessários. Além disso, deve-se pensar em análises estatísticas de consultas e empréstimos.

A questão da posse dos objetos informacionais é uma das maiores preocupações dos bibliotecários. Convencionalmente, os materiais bibliográficos eram produtos manufaturados e sua exploração, armazenamento, difusão, disseminação, circulação e uso eram determinados pelas bibliotecas. Contudo, os modelos de negócios apresentados pelas editoras para as unidades de informação são realizados através de licenciamentos. Dessa forma, como cita Barros (2013) as licenças são regidas sob "as leis dos contratos, não exatamente as leis de direitos autorais, e como tal podem impor restrições adicionais". Grigson (2011) observa que a maioria dos modelos de negócios impõe limite para o uso, limitando o número de usuários que podem acessar o e-book, ao mesmo tempo, ou o número de vezes que o livro pode ser acessado dentro de um determinado período de tempo.

Grigson (2011) complementa "alguns limites dos editores recaem sobre a capacidade dos usuários para baixar ou imprimir todas ou seções de um e-book". Assim sendo, a biblioteca deixa de exercer seu papel de instituição que armazena, organiza e distribui o conhecimento passando para gestora de arquivos das editoras. Existem ainda, necessidades relacionadas com o gerenciamento dos livros digitais referentes a circulação, empréstimo, catalogação e preservação. Essas questões necessitam de debate para que haja uma uniformização dos procedimentos entre e para todas as bibliotecas.

\section{CONSIDERAÇÕES FINAIS}

O comércio dos e-books apresenta problemas relacionados com seus consumidores: há carência de estudos ou pesquisas de mercado relacionadas aos leitores. Dessa forma, o negócio fica pulverizado e explorado de forma reduzida ou para um nicho do mercado. Assim, os leitores não são acolhidos em suas perspectivas de consumo. Para Melo (2012) entre os profissionais do setor editorial, em particular no vasto segmento de obras gerais, é comum a avaliação de que muito pouco se conhece sobre o consumidor de livros. Quanto às editoras existem dificuldades relacionadas com os níveis de capitalização; problemas com a entrada de grandes grupos internacionais de editores; poucas empresas com o capital aberto, empresas com gestão amadora ou familiar. O mercado apresenta um cenário com perspectivas para monopólio de grandes empresas multinacionais dominando os negócios. Dessa forma, para as editoras nacionais as parcerias são fundamentais para sua manutenção.

Em vista do panorama apresentado, verifica-se que muito há de ser feito para a expansão dos e-books na sociedade brasileira. É fundamental uma mudança na forma de pensar dos membros da cadeia dos livros digitais. O comportamento deve ser inclusivo e democrático, a ampliação do uso dos e-books favorecerá dos integrantes do mercado livreiro. Nesse sentido, a união entre bibliotecários, editores, autores, governo e consumidores é fator determinante para o sucesso dos livros em formato digital. A preocupação na criação de uma política governamental para expansão dos livros digitais torna-se relevante. Além disso, uma alteração comportamental dos bibliotecários no tangente a participação ativa nos processos que envolvem a forma e o desenvolvimento de coleções digitais são fundamentais para o sucesso da empreitada desse novo suporte informacional. 


\section{REFERENCIAS}

ALONSO ARÉVALO, Júlio; CORDÓN GARCIA, José. El libro electrónico y los DRM. Anuário ThinkEPI, 2010.

BARROS, Moreno. Bibliotecário e e-books. Revista Biblio Cultura Informacional, 2013. Disponível em: <http://biblioo.info/bibliotecarios-e-ebooks/>. Acesso em: 15 jun. 2015.

BONEZI, Luciane Adami. Usabilidade dos livros eletrônicos: um estudo de caso com os alunos do curso de Biblioteconomia da UDESC. Florianópolis, 2007. 75 p. Monografia. (Bacharel em Biblioteconomia) - Habilitação em Gestão da Informação , UDESC, Santa Catarina, 2007.

CUNHA, Murilo Bastos da. Desafios na construção de uma biblioteca digital. Ci. Inf., Brasília, v. 28, n. 3, p. 257-268, set./dez. 1999

DINIZ, Eduardo. Governo digital na América Latina, 2002. Disponível em: <www.conip.com.br>. Acesso em: 08 mar. 2016.

DUARTE, Adriana Bogliolo Siri. Livro eletrônico : pesquisa com bibliotecários, 2007. Disponível em: < http://bogliolo.eci.ufmg.br/downloads/TGI061\%20aula\%205.pdf>. Acesso em: 04 mar. 2016.

DZIEKANIAK, Gisele Vasconcelos. Considerações sobre o e-book: do hipertexto à preservação digital. Biblos: Revista do Instituto de Ciências Humanas e da Informação, n. 2, v. 1, p. 83-99, 2010.

GRIGSON, Anna. An introduction to e-book business models and suppliers. In: PRICE, Kate; HAVERGAL, Virgina (Ed.). E-books in libraries: a practical guide. London: Facet, 2011. p. 19-36.

IANZEN, Adriana; PINTO, José Simão de Paula.; WILDAUR Egon Walter. Os sistemas de proteção de direito digital (DRM): tecnologias e tendências para e-books. Encontros Bibli: revista eletrônica de biblioteconomia e ciência da informação, v. 18, n. 36, p.203-230, jan./abr., 2013.

IDEC; CENTRO DE TECNOLOGIA E SOCIEDADE; FGV DIREITO RIO. Campanha Restrições Tecnológicas: você paga e leva menos. 2007. Disponível em: http://www.idec.org.br/em-acao/em-foco/restricoes-tecnologicas-voce-paga-e-leva-menos.

Acesso em: 27 out. 2015.

IFLA. IFLA principles for library e-lending. In: IFLA WORLD LIBRARY AND INFORMATION CONGRESS: IFLA General Conference and Assembly, 79., Singapura. Anais... Singapura: 2013.

LIMA, Graziela dos Santos; FELDMAN, Daniele.; JULIANI, Jordan Paulesky. Os e-books nas bibliotecas universitárias federais do brasil. Revista ACB: Biblioteconomia em Santa Catarina, v. 20, n. 2, p. 313-320, 2015. Disponível em: <http://basessibi.c3sl.ufpr.br/brapci/v/17774>. Acesso em: 05 Jun. 2016. 
MARREIROS, Luiz. Gestão de direitos digitais, 2007. Disponível em: $<$ http://www.apdsi.pt/uploads/news/id145/gest\%C3\%A3o\%20direitos\%20digitais_2053_200 70628.pdf>. Acesso em: 28 set. 2015.

MARTINS, Robson Dias. Proposta teórica de criação de plataforma de gerenciamento de e-books. 2015. 124f. Dissertação. (Mestrado profissional em Biblioteconomia) Universidade Federal do Estado do Rio de Janeiro, Rio de Janeiro, 2015.

MARTINS, Robson Dias; SCAVARDA, Annibal. Ebooks supply chain : uma análise de processos no desenvolvimento de coleções. Bussiness Management Review (BMR), v. 4, p.168-178, 2015.

MELO, Gustavo. Desafios para o setor editorial brasileiro de livros na era digital. BNDES Setorial, Rio de Janeiro, v. 36, n. 00, p.429-473, set. 2012.

PINHEIRO, Patrícia Peck.; SLEIMAN, Cristina. Tudo o que você precisa saber sobre direito digital no dia a dia. São Paulo: Saraiva, 2009.

PONTES, Samantha. Modelo de contratos para aquisição e/ou assinatura de publicações eletrônicas. In: Reunião técnica do Grupo de profissionais em Informação e Documentação Jurídica do Rio de Janeiro, 1, 2015. Disponível em: <http://gidjrj.com.br/wpcontent/uploads/2015/08/Reuni\%C3\%A3o-T\%C3\%A9cnica-2015-Modelos-de-Contratospor-Samantha-Pontes.pdf>. Acesso em: 01 jul. 2016.

PROCÓPIO, Ednei. A revolução dos e-books: a indústria dos livros da era digital. São Paulo: SENAI-SP, 2013.

RAO, Siriginidi Subba. Eletronic Books: a review and evaluation. Library Hi Tech, v. 21, n. 1, p. 85-93. 2003.

RODRIGUES, Charles et al. E-books didáticos nos ambientes de aprendizagem em rede. Revista da Faculdade de Biblioteconomia e Comunicação da UFRGS v. 21, n. 1, Jan./Abr. 2015.

SILVA, Ronaldo Alves da. E-books em bibliotecas: novos desafios para os bibliotecários, 2013. Disponível em: < https://portal.febab.org.br/anais/article/download/1398/1399>. Acesso em: 20 maio 2016.

SCALCO, Lucia Mury. Máquinas, conexões e saberes: as práticas de "inclusão digital" em famílias de grupos populares. 2012. 260f. Tese. (Doutorado em Antropologia Social). Universidade do Rio Grande do Sul, Porto Alegre, 2012.

VENTURA, Glaucia. A aventura do livros: vantagens e desvantagens de sua viagem pelo meio eletrônico, 2000. Disponível em: http://www.ccuec.unicamp.br/revista/infotec/artigos/glaucia.html>. Acesso em: 3 mar. 2016.

VERGUEIRO, Waldomiro. O futuro das bibliotecas e o desenvolvimento de coleções: perspectivas de atuação para uma realidade em efervescência. Perspectivas em Ciência da Informação, Belo Horizonte, v. 2, n. 1, p. 93-107, jan./jun. 1997. 
WHITE, G. W.; CRAWFORD, G. A. Developing an electronic information resources collection development policy.Asian Libraries, Bingley.UK, v. 6, n. 1/2, p. 51-56, jan. 1997. Disponível em:

$<$ http://www.emeraldinsight.com/journals.htm? articleid=861022\&show=abstract $>$. Acesso em: 20 jan. 2015.
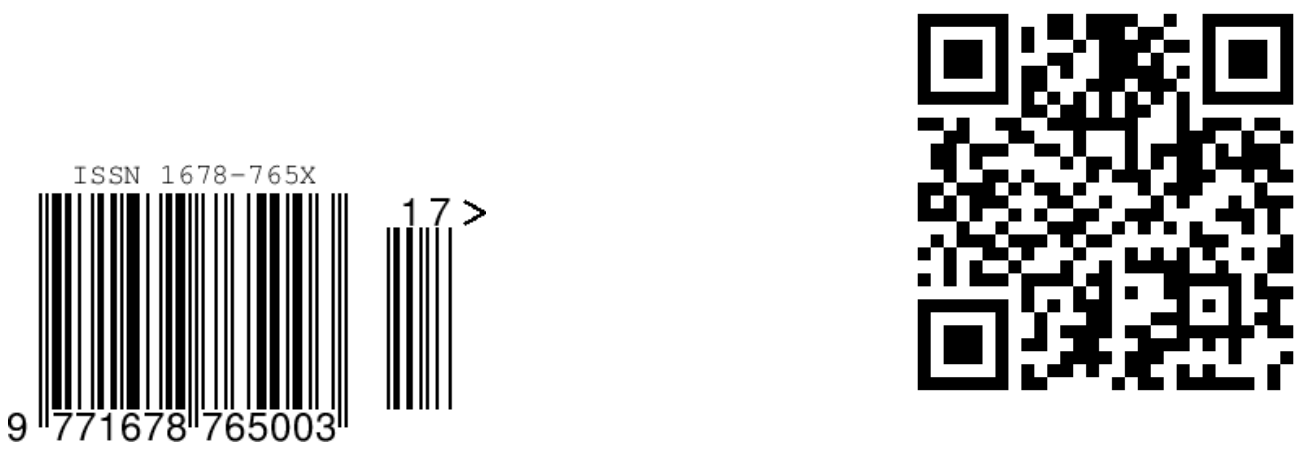